\section{Final diagnosis}

Thoracic actinomycosis.
Keywords: actinomycosis; thoracic wall; anaerobes; abscess
1 Finegold SM. Anaerobic bacteria: General concepts. In: Mandell GL, Bennett JE, Dolin R, eds. Principles and practice of infectious diseases. New York: Churchill Livingstone, 1995; pp 2156-73.

2 Heffner JE, Harley RA. Thoracic actinomycosis. Semin Respir Med 1992;13:234-41.

3 Russso TA. Agents of actinomycosis. In: Mandell GL, Bennett JE, Dolin R, eds. Principles and practice of infectious diseases. New York: Churchill Livingstone, 1995; pp 2280-8.
4 Kwong JS, Muller NL, Godwin JD, Aberle D, Grymaloski MR. Thoracic actinomycosis: CT findings in eight patients. Radiology 1992;183:189-92.

5 Pinto MM, Longstreth GB, Khoury GM. Fine needle aspiration of Actinomyces infection of the breast. A novel presentation of thoracopleural actinomycosis. Acta Cytol 1991; 35:409-11.

\title{
Haematemesis and chest pain in a middle-aged woman
}

\author{
P A Kitchen, M R Jacyna
}

A 57-year-old woman presented with acute-onset sharp retrosternal chest pain which occurred whilst walking. The pain radiated to her back and was associated with coffee-ground vomiting. She had eaten a meal two hours before with no discomfort. There was no previous history of ischaemic heart disease, hypertension, peptic ulcer disease or gastro-oesophageal reflux disease and she was not taking aspirin or any other nonsteroidal anti-inflammatory drug.

On examination she was well and had no surgical emphysema. The pulse was $90 \mathrm{beats} / \mathrm{min}$ and the blood pressure $150 / 85 \mathrm{mmHg}$ being equal in both arms. The respiratory and abdominal system were unremarkable. Routine biochemical and haematological parameters were normal apart from a haemoglobin of $11.8 \mathrm{~g} / \mathrm{dl}$ and a mean corpuscular volume of $88 \mathrm{fl}$. Her C-reactive protein (CRP) was $28 \mathrm{mg} / \mathrm{l}$. The chest X-ray and electrocardiogram were normal. She was then kept nil by mouth and intravenous fluids were started. She then had an urgent oesophagogastroduodenoscopy which showed a submucosal haematoma extending from 18-40 cm (figure 1). On retroversion of the endoscope there was an ulcerative area at the cardia, histology of which showed fibrinous debris but no evidence of malignancy. Computed tomography (CT) scan of the thorax showed a dilated proximal oesophagus with oesophageal wall thickening which narrowed to the level of the left pulmonary artery but no evidence of pathological lymph nodes or masses.

Department of Gastroenterology, Northwick Park and St Marks Hospital NHS Trust, Watford Road, Harrow, Middlesex HA1 3UJ, UK P A Kitchen M R Jacyna

Accepted 20 August 1997
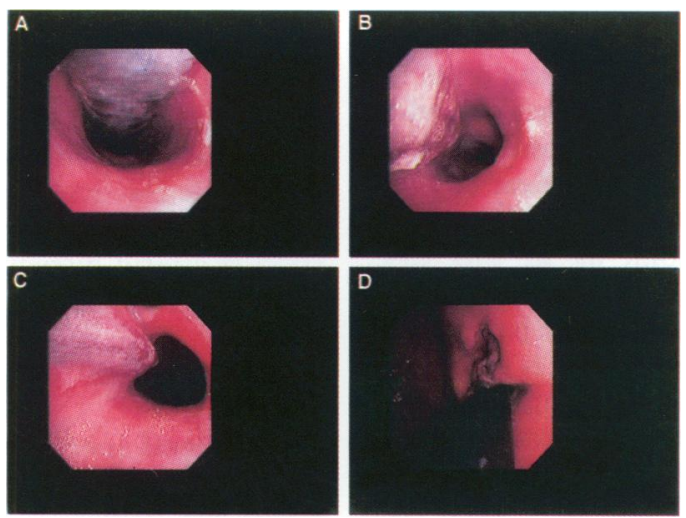

Figure 1 (A) Proximal portion of haematoma at 20 $\mathrm{cm}$; (B) view at $35 \mathrm{~cm}$; (C) distal portion at $40 \mathrm{~cm}$; (D) ulcerative area seen on retroverting the endoscope

\section{Questions}

1 What is the diagnosis?

2 What is the treatment? 


\section{Answers}

\section{QUESTION}

Oesophageal apoplexy.

\section{QUESTION 2}

The treatment of oesophageal apoplexy is conservative. This involves keeping the patient nil by mouth, instituting intravenous fluids and occasionally the use of blood transfusions. Acid suppression is empirically carried out with $\mathrm{H} 2$ antagonists, such as ranitidine. This should theoretically decrease acid reflux and aid healing of the oesophageal mucosa. Antibiotics should be considered if there is a fever. Surgical intervention is often fruitless and occasionally hazardous. ${ }^{1}$ Such a conservative treatment approach was instigated in our patient, who made a full recovery (figure 2 ).
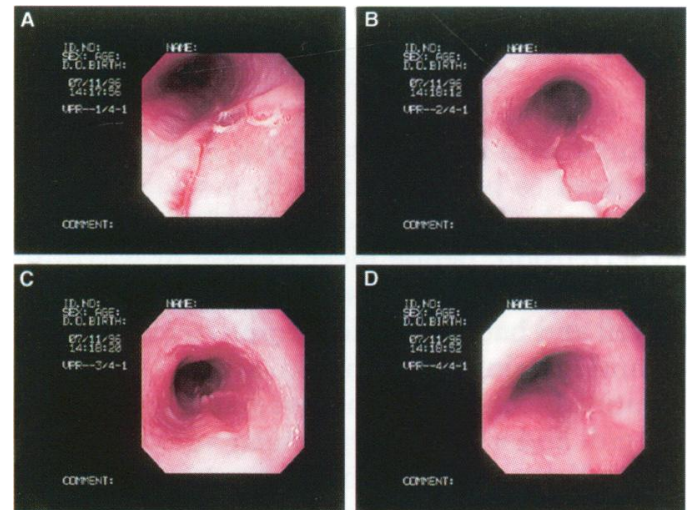

Figure 2 View at $35 \mathrm{~cm}(\mathrm{~A}), 30 \mathrm{~cm}(\mathrm{~B}), 20 \mathrm{~cm}(\mathrm{C})$, and $15 \mathrm{~cm}$ (D) after conservative treatment

\section{Discussion}

Oesophageal apoplexy is a term used to describe the development of a spontaneous intramural haematoma of the oesophagus. This leads to varying degrees of submucosal dissection of the oesophageal wall. The term was first coined by Tally and Nicks in 1969 but the condition itself was first described by Marks and Keat in 1968. This is a rare condition, commonly presenting in women over 50 years old, as in this case. However there have been some case reports of this condition occurring in younger patients.

The most common presentation is with sharp retrosternal chest pain which may radiate to the back. Haematemesis is the next most common presentation occurring in $70 \%$ of patients and is often of small volume. There have been case reports where blood transfusions have been

1 Kerr WF. Spontaneous intramural rupture and intramural haematoma of the oesophagus. Thorax 1980;35:890-7.

2 Steadman J, Kurling P, Crimmins F, et al. Spontaneous intramural rupture of the oesophagus. Gut 1980;30:845-9.

3 Kelley DL, Neugebauer MK, Fosburg RG. Spontaneous intramural esophageal perforation. $₹$ Thorac Cardiovasc Surg intramural eso

4 Kudy WVC. Spontaneous intramural perforation of the

4 Kudy WVC. Spontaneous intramural perforation of the
esophagus: case report and review of the literature. esophagus: case report
Endoscopy1 $1989 ; 21: 153$.

\begin{tabular}{|l|}
\hline Summary points \\
\hline oesophageal apoplexy is a rare cause of \\
haematemesis and chest pain which can be \\
treated conservatively \\
endoscopy is a useful way of confirming the \\
diagnosis
\end{tabular}

required but this is rare. ${ }^{1}$ Patients may also present with acute dysphagia and odynophagia.

The aetiology of this condition is unclear, although three possible theories have been put forward. The first is that there is submucosal haemorrhage due to a possible vascular abnormality. To support this theory oesophageal apoplexy has been associated with caveno-capillary haemangiomatosis. Another possibility is that oesophageal apoplexy lies on a spectrum between Mallory-Weiss syndrome and Bornholm's disease. This is unlikely though, as these two conditions are both associated with profuse vomiting prior to developing other symptoms. An abnormal swallowing mechanism has also been suggested as there has been an association with symptoms occurring after eating and drinking but manometry performed in these patients has been reported as normal. ${ }^{2}$ In our case, it was interesting that the CRP was raised and this suggests a possible association with infection. Associations with upper respiratory tract infections have been described in other case reports. ${ }^{34}$ The other possibility is that this CRP rise is due to the large submucosal bleed.

When the diagnosis is missed, the management of the presumed diagnosis is often more aggressive. This is well illustrated in the literature. In one case, an endoscopist mistakenly performed an oesophageal biopsy, which led to severe gastrointestinal bleeding requiring an emergency oesophagectomy. ${ }^{5}$ Another reported misdiagnosis was a dissecting aortic aneurysm, which resulted in a left lateral thoracotomy being performed. ${ }^{6}$ A further report describes a patient who was diagnosed with an oesophageal carcinoma ${ }^{7}$ and told to 'put his house in order', the diagnosis being based purely on a CT scan. The main reason for misdiagnosis is that oesophageal apoplexy is a rare condition and endoscopists may not recognise the classical appearance. Another problem is that it mimics common emergencies such as aortic dissection, Bornholm's disease and oesophageal malignancy.

\section{Final diagnosis}

\section{Oesophageal apoplexy.}

Keywords: oesophageal apoplexy; endoscopy; haematemesis; chest pain

5 Scully R, Mark E, McNealy W, McNealy B. Case records of the Massachusetts General Hospital. $N$ Engl $\mathcal{F}$ Med 1989;321:1249-59.

6 Sen A, Lea RE. Spontaneous oesophageal haematoma: a review of the difficult diagnosis. Ann R Coll Surg Engl 1993; 75;293-5.

7 Meulman N, Evans J, Watson A. Spontaneous intramura haematoma of the oesophagus: a report of three cases and review of the literature. Aust NZ $¥$ Surg 1994;64:190-3. 